\title{
Monozygotic twins with Neurofibromatosis type 1 , concordant phenotype and synchronous development of MPNST and metastasis
}

\author{
German Melean ${ }^{1}$, Alba Marina Hernández', María Carmen Valero 1,2, Elisabete Hernández-Imaz', Yolanda Martín, \\ Concepción Hernández-Chico ${ }^{1 *}$
}

\begin{abstract}
Background: Neurofibromatosis type 1 is a common autosomal dominant disorder with full penetrance and variable expression. The condition predisposes individuals to the development of malignant nervous system tumours, most frequently Malignant Peripheral Nerve Sheath Tumours (MPNSTs). Previous studies indicate that genetic factors other than mutations in NF1 may be responsible for the condition's variable expression.

Case report: Here we present data from a pair of monozygotic twins affected by Neurofibromatosis type 1 resulting from a de novo mutation. Both twins developed a left sciatic plexiform neurofibroma that evolved into MPNST at a similar age and they also developed pulmonary metastasis at the same age. Other concordant traits between the twins were: macrocephaly, psychomotor delay, café-au-lait spots, cutaneous neurofibromas, retroperitoneal, pleural and paraspinal neurofibromas. The main discordant features observed were tibial pseudoarthrosis, pectus carinatum, osteoporosis and thymus hyperplasia.

Conclusions: This is the first report of monozygotic twins with Neurofibromatosis type 1 that develop MPNSTs, the localization and chronological evolution of which, and its metastasis, is concordant in both twins. These cases suggest that the events involved in the transformation of benign plexiform neurofibromas to MPNSTs in Neurofibromatosis type 1, follow a spatiotemporally programme that is influenced by heritable factors other than NF1 mutations.
\end{abstract}

\section{Background}

Neurofibromatosis type 1 (NF1, MIM \#162200) is a common autosomal dominant disorder that affects about 1 in 3,500 individuals worldwide, predisposing individuals to develop tumours in the nervous system. The condition is caused by mutations in the NF1 gene located at $17 \mathrm{q} 11.2$ that encodes neurofibromin, a 2,818 amino acid GTPase activating protein (GAP) which regulates $p 21$-ras proto-oncogene activity [1]. About half of the NF1 cases represent de novo mutations.

NF1 is a fully penetrant condition although its presentation is variable. The main defining features are

\footnotetext{
* Correspondence: chernandez.hrc@salud.madrid.org

'Unidad de Genética Molecular, Hospital Ramón y Cajal, Instituto Ramón y

Cajal de Investigación Sanitaria (IRYCIS) and Centro de Investigación Biomédica en Red de Enfermedades Raras (CIBERER), Instituto de Salud

Carlos III, Spain

Full list of author information is available at the end of the article
}

multiple "café au lait" spots (CLS), skin fold freckling, Lisch nodules and cutaneous neurofibromas [2]. Plexiform neurofibromas (PNFs) and optic gliomas are also common neoplastic manifestations associated with NF1. In NF1 patients, between 10-15\% of the PNFs transform into Malignant Peripheral Nerve Sheath Tumours (MPNSTs) [3], which in turn metastasize in an early phase and are associated with a poor prognosis [4]. Other features associated with the condition are learning disabilities, macrocephaly, scoliosis, pseudoarthrosis and epilepsy.

Although many different mutations have been reported in NF1 [5], no genotype-phenotype relationships have been found, except for large deletions encompassing the entire NF1 gene and its flanking chromosomal regions (NF1 microdeletions), or a 3 bp deletion in exon 17 of NF1 (c.2970-2972delAAT; p.990delM). NF1 microdeletions are associated with the appearance of a large number 
of cutaneous neurofibromas, dysmorphic features, learning disabilities and an elevated risk of MPNSTs [6,7]. By contrast, the small deletion in exon 17 is associated with a milder phenotype and the absence of neurofibromas [8].

A contribution of modifying genes not linked to the NF1 locus might explain the variable expression of this condition. This hypothesis is supported by phenotype correlation studies in different groups of affected relatives, including monozygotic (MZ) twins $[9,10]$, and through the analysis of intrafamilial associations between the clinical features of NF1 [11,12].

Better understanding of MPNST variable occurrence in NF1 has been elusive, due to the tumor's low frequency and the uncommon presentation in multiple members of the same family. Here we report an illustrative case of NF1 MZ twins with PNF in similar anatomical location that transformed to MPNST and produced pulmonary metastasis, simultaneously in both twins.

\section{Case Report}

Two 27 year-old male MZ twins were referred to our Unit for molecular analysis of the NF1 gene. The probands were born after an uncomplicated pregnancy to healthy non-consanguineous unaffected parents, with no prior family history of NF1. The twins have an unaffected brother 4-years older who suffered mild psychomotor delay and dysphasia in early childhood. The twins grew to adulthood and they are currently still living together.

Both twins presented with minimal cutaneous manifestations, including approximately 15 CLS and a few cutaneous neurofibromas (detailed clinical data is reported in Table 1). A relevant tumour phenotype was observed in both twins. In "Twin 1", MRI performed at 20 years of age detected one PNF of the left sciatic popliteal nerve and many small neurofibromas in both legs surrounding the femoropopliteous vessels. Although the PNF was resected due to the distal pain in the leg, at 22 years of age a further surgical intervention was performed to resect a tumour detected by MRI in the same region. Pathological analysis of the resected tissue diagnosed a MPNST of the sciatic popliteal nerve and a PNF. Although the patient was subjected to a cycle of radiotherapy after surgery, the MPNST recurred twice 2 and 4 years later. These tumours were treated surgically, leading to the amputation of the left leg in the last operation. In "Twin 2", MRI examination at 20 years of age identified bilateral PNFs of the sciatic nerves and at 24 years of age, the tumour in the left leg was surgically resected due to its rapid growth and malignant radiological aspect. The pathological analysis of the resected tissue diagnosed high grade MPNST of the left sciatic nerve and hence, a cycle of radiotherapy was administered after surgery.
A pulmonary metastatic MPNST was detected in both twins at 27 years of age. "Twin 1" developed the metastasis in the lower lobule of the right lung, while "Twin 2 " presented the metastasis in the upper lobe of the left lung. The concordant and discordant manifestations associated with NF1 in these twins are presented in Table 1.

\section{Mutational NF1 analysis and twins' zygosity test}

Lymphocyte RNA was obtained from fresh peripheral blood and RT-PCR was performed to amplify overlapping cDNA fragments that covered the entire gene. The PCR products were analyzed by Denaturing High Performance Liquid Chromatography (DHPLC) and the positive fragments in the DHPLC analysis were sequenced. The mutations found were confirmed by direct sequencing of the genomic DNA and in this way, the c. $4537 \mathrm{C} \rightarrow \mathrm{T}$ mutation (Arg1513X) was found in exon $27 \mathrm{a}$ of the NF1 gene from both twins. The mutation was not present in the twins' parents or brother.

Twins' zygosity was confirmed by analysing 14 polymorphic microsatellite markers at different chromosomal loci. Informed consent for genetic analysis was obtained from all family members included in this study.

\section{Case Discussion}

We report here a pair of NF1 MZ twins with remarkable concordance in their tumour phenotype. The c. $4537 \mathrm{C} \rightarrow \mathrm{T}$ disease-causing mutation was found in both twins and it is a nonsense mutation that has been recurrently found in subjects with NF1 [13], although it does not appear to be associated with any particular clinical feature of the disease.

Macrocephaly, CLS and cutaneous neurofibromas are concordant traits in our twins, as was reported previously in a cohort of six MZ twin pairs [9]. Concordance among more distant relatives was weaker, indicating that genetic factors other than the mutant NF1 allele influence the expression of these traits [9-11]. Psychomotor delay and learning disabilities develop in $30-60 \%$ of individuals affected by NF1, and learning disabilities were seen to be $100 \%$ concordant in NF1 MZ twins $[9,10]$. In this sense, our probands presented similar alterations, although both responded well to therapy. However, it is not possible to confirm that this feature is associated with NF1 as the twins' older unaffected brother also displayed learning problems during early childhood and responded well to therapy.

Scoliosis and tibial dysplasia were only evident in "Twin 1", consistent with the low correlation coefficient of 0.17 established in $6 \mathrm{MZ}$ twins [10], even though scoliosis was previously reported to be a concordant feature in another 3/3 NF1 MZ twins [9]. There is no prior information on tibial dysplasia in MZ twins with NF1 
Table 1 Clinical features of "Twin 1" and "Twin 2"

\begin{tabular}{|c|c|c|c|}
\hline Age at diagnosis & FEATURE & TWIN 1 & TWIN 2 \\
\hline \multirow[t]{5}{*}{ At birth } & $\mathrm{CLS}$ & + & + \\
\hline & Macrocephaly & + & + \\
\hline & Pectus carinatum & + & - \\
\hline & Scoliosis & + & - \\
\hline & Tibial pseudoarthrosis & + & - \\
\hline \multirow[t]{10}{*}{ Childhood } & Mild psychomotor delay & + & + \\
\hline & Developmental dysphasia & + & + \\
\hline & Hyperkinesia/attention disorder & + & + \\
\hline & Hypotonia & - & + \\
\hline & Strabismus & - & + \\
\hline & Dental development delay & + & - \\
\hline & Right valgus foot & + & + \\
\hline & Bilateral flat feet & + & + \\
\hline & Normal cranial CT & + & + \\
\hline & Normal ophthalmologic examination & + & + \\
\hline $14 \mathrm{Y} / \mathrm{O}$ & Radial intraneural neurofibroma & + & - \\
\hline \multirow[t]{2}{*}{$20 \mathrm{Y} / \mathrm{O}$} & Plexiform neurofibroma of the left sciatic nerve & + & $\begin{array}{c}+ \\
\text { (bilateral) }\end{array}$ \\
\hline & Multiple neurofibromas surrounding femoropopliteous vessels & + & - \\
\hline $22-24 Y / O$ & MPNST of the left sciatic nerve & $+(22 \mathrm{Y} / O)$ & $+(24 \mathrm{Y} / \mathrm{O})$ \\
\hline \multirow[t]{10}{*}{$24-27 \mathrm{Y} / \mathrm{O}$} & MPNST recurrences & + & - \\
\hline & Osteoporosis & - & + \\
\hline & Thymus hyperplasia & - & + \\
\hline & Bilateral gynecomastia & - & + \\
\hline & Left lung focal pleural thickening & + & + \\
\hline & Pleural neurofibroma & + (multiple) & + (one) \\
\hline & Hepatic hypodense lesion & + & + \\
\hline & Paraspinal plexiform neurofibroma & - & + \\
\hline & Psoas plexiform neurofibroma & + & - \\
\hline & Multiple retroperitoneal neurofibromas & + & + \\
\hline $27 \mathrm{Y} / \mathrm{O}$ & Pulmonary MPNST metastasis & + (right lung) & + (left lung) \\
\hline
\end{tabular}

and the osteoporosis developed by "Twin 2" is probably associated with parathyroid gland disease [14].

PNFs were previously found to have a strong concordance among NF1 MZ twins, yet while concordance was lower in more distant relatives, loci other than NF1 were thought to modulate this feature $[9,10]$. Our observations are in accordance with such an influence.

To our knowledge, this is the first report of NF1 MZ twins with MPNSTs and what is more, both twins developed MPNSTs at similar ages and at the same sciatic PNF location. Indeed, pulmonary metastases also appeared simultaneously in both twins at 27 years of age. Significantly, "Twin 2" developed another PNF in the right sciatic nerve that is still under surveillance.

Our current understanding of the molecular mechanisms underlying PNF transformation into a MPNST is still limited. Two events seem to be essential for the development of NF1 tumours: the inactivation of the remaining wild type NF1 allele (somatic mutation) in a schwann cell precursor; and a tumour microenvironment produced by the NF1 haploinsufficency in other tumoural elements (fibroblasts, perineural-like fibroblasts and mast cells). This microenvironment provides crucial mitogenic signals to homozygous mutated NF1 schwann cells [15]. In addition to the double mutation of the NF1 gene, additional genetic alterations also seem to be required to permit the transformation of benign PNF into MPNST. These alterations include inactivation of cell-cycle associated genes such as TP53, RB1 and $C D K N 2 A$ which encodes $\mathrm{p} 16(I N K 4 A)$ and $\mathrm{p} 14(A R F)$ $[16,17]$. However, a recent study reported $\mathrm{LOH}$ of TP53 and $R B 1$ in a minority of cutaneous neurofibromas $(4.5$ and $1.1 \%$ respectively) [16]. Gene expression profiling in NF1-associated benign and malignant tumours identified relatively widespread deregulation of genes in developing schawnn cells and in particular, the SOX9 gene seems to 
be essential for MPNST cell survival [18]. Microsatellite instability (MSI) has also been associated with peripheral nerve NF1 tumours, both benign and malignant $[16,19]$ Malignant tumours present higher levels of MSI than benign ones and these findings suggest that mismatch repair genes (MMR) may also participate in the malignant transformation of NF1-associated tumours [20,21]. Unfortunately, we could not perform further molecular investigations in our twins since no further tumour tissue was available.

The most exceptional feature in our twins is that concordance was not only detected in terms of the presence of a MPNST in both twins but also, in the location and chronological evolution. An interesting theory has been proposed that may be related with this concordance, based on the assumption that the potential for angiogenesis varies spatiotemporally in different vascular fields. Hence, it was suggested that NF1 deficiency may disrupt some vascular fields, producing anatomical regions that are prone to develop tumours and malformations [22].

Previous reports in $\mathrm{MZ}$ twins with $B R C A 1$ and $B R C A 2$ mutations suggest that an analogous regulated program may also occur in other kinds of hereditary tumours. Similar to this case, in MZ twins with mutations in $B R C A 1$ and BRCA2 tumours were detected at the same approximate location and same age [23,24].

\section{Conclusions}

For the first time, we report NF1 MZ twins concordant for MPNSTs, with a similar clinical presentation of sciatic nerve PNF, as well as a similar malignant and metastatic evolution. This case indicates that the events needed for the transformation of a PNF to MPNST, and their subsequent metastasis, follow a chronological and spatially regulated programme, where heritable factors other than the NF1 mutation exert a strong influence.

\section{Acknowledgements \\ We would like to thank the family and the "Asociación de Afectados de Neurofibromatosis" (AANF) for being so encouraging during this work. This study was supported by the Asociación de Afectados de Neurofibromatosis (AANF) and the Fundación Mutua Madrileña (FMM). GM is supported by a grant of the "Fundación Carolina" and AMH by the AANF. EHI is fellowhip of the Departamento de Educación, Universidades e Investigación del Gobierno Vasco. Written consent was obtained from the patients for the publication of this report.}

\section{Author details}

'Unidad de Genética Molecular, Hospital Ramón y Cajal, Instituto Ramón y Cajal de Investigación Sanitaria (IRYCIS) and Centro de Investigación Biomédica en Red de Enfermedades Raras (CIBERER), Instituto de Salud Carlos III, Spain. ${ }^{2}$ Beckman Institute, University of Illinois at UrbanaChampaign, USA.

\section{Authors' contributions}

$\mathbf{G M}$ and $\mathbf{A M H}$ were involved in the patient management and writing of the article; $\mathbf{M C V}$, EHI and YM in the molecular analysis and critical revision of the manuscript; and CHC was responsible for overseeing the study, and for the writing and the critical revision of the article. All authors read and approved this manuscript.

\section{Competing interests}

The authors declare that they have no competing interests.

Received: 24 February 2010 Accepted: 5 August 2010

Published: 5 August 2010

\section{References}

1. Ballester R, Marchuk D, Boguski M, Saulino A, Letcher R, Wigler M, Collins F: The NF1 locus encodes a protein functionally related to mammalian GAP and yeast IRA proteins. Cell 1990, 63:851-859.

2. Williams VC, Lucas J, Babcock MA, Gutmann DH, Korf B, Maria BL Neurofibromatosis type 1 revisited. Pediatrics 2009, 123:124-133.

3. Upadhyaya M, Spurlock G, Monem B, Thomas N, Friedrich RE, Kluwe L, Mautner V: Germline and somatic NF1 gene mutations in plexiform neurofibromas. Hum Mutat 2008, 29:E103-E111.

4. Ferner RE, Gutmann DH: International consensus statement on malignant peripheral nerve sheath tumors in neurofibromatosis. Cancer Res 2002, 62:1573-1577.

5. Thomson SA, Fishbein L, Wallace MR: NF1 mutations and molecular testing. J Child Neuro 2002, 17:555-561.

6. Valero MC, Pascual-Castroviejo I, Velasco E, Moreno F, Hernández-Chico C: Identification of de novo deletions at the NF1 gene: no preferential paternal origin and phenotypic analysis of patients. Hum Genet 1997, 99:720-726.

7. Pasmant E, Sabbagh A, Spurlock G, Laurendeau I, Grillo E, Hamel MJ, Martin L, Barbarot S, Leheup B, Rodriguez D, Lacombe D, Dollfus H, Pasquier L, Isidor B, Ferkal S, Soulier J, Sanson M, Dieux-Coeslier A, Bièche I, Parfait B, Vidaud M, Wolkenstein P, Upadhyaya M, Vidaud D, members of the NF France Network: NF1 microdeletions in neurofibromatosis type 1: from genotype to phenotype. Hum Mutat 2010, 31:E1506-E1518.

8. Upadhyaya M, Huson SM, Davies M, Thomas N, Chuzhanova N, Giovannini S, Evans DG, Howard E, Kerr B, Griffiths S, Consoli C, Side L, Adams D, Pierpont M, Hachen R, Barnicoat A, Li H, Wallace $P$, Van Biervliet JP, Stevenson D, Viskochil D, Baralle D, Haan E, Riccardi V, Turnpenny $P$, Lazaro $C$, Messiaen L: An absence of cutaneous neurofibromas associated with a 3-bp inframe deletion in exon 17 of the NF1 gene (c.2970-2972 delAAT): evidence of a clinically significant NF1 genotype-phenotype correlation. Am J Hum Genet 2007, 80:140-151.

9. Easton DF, Ponder MA, Huson SM, Ponder BA: An analysis of variation in expression of neurofibromatosis (NF) type 1 (NF1): evidence for modifying genes. Am J Hum Genet 1993, 53:305-301.

10. Sabbagh A, Pasmant E, Laurendeau I, Parfait B, Barbarot S, Guillot B, Combemale P, Ferkal S, Vidaud M, Aubourg P, Vidaud D, Wolkenstein P, members of the NF France Network: Unravelling the genetic basis of variable clinical expression in neurofibromatosis 1. Hum Mol Genet 2009, 18:2768-2778.

11. Szudek J, Joe H, Friedman JM: Analysis of intrafamilial phenotypic variation in neurofibromatosis 1 (NF1). Genet Epidemiol 2002, 23:150-164

12. Szudek J, Evans DG, Friedman JM: Patterns of associations of clinical features in neurofibromatosis 1 (NF1). Hum Genet 2003, 112:289-297.

13. Fahsold R, Hoffmeyer S, Mischung C, Gille C, Ehlers C, Kücükceylan N, Abdel-Nour M, Gewies A, Peters H, Kaufmann D, Buske A, Tinschert S, Nürnberg P: Minor lesion mutational spectrum of the entire NF1 gene does not explain its high mutability but points to a functional domain upstream of the GAP-related domain. Am J Hum Genet 2000, 66:790-818

14. Bahadir C, Gürleyik G, Ocak E: Neurofibromatosis type 1 and primary hyperparathyroidism with spinal deformity and osteoporosis. Acta Chir Belg 2009, 109:123-125

15. Carroll SL, Ratner N: How does the Schwann cell lineage form tumors in NF1? Glia 2008, 56:1590-1605.

16. Thomas L, Kluwe L, Chuzhanova N, Mautner V, Upadhyaya M: Analysis of NF1 somatic mutations in cutaneous neurofibromas from patients with high tumor burden. Neurogenetics

17. Spurlock G, Knight SJ, Thomas N, Kiehl TR, Guha A, Upadhyaya M: Molecular evolution of a neurofibroma to malignant peripheral nerve sheath tumor (MPNST) in an NF1 patient: correlation between histopathological, clinical and molecular findings. J Cancer Res Clin Oncol 
18. Miller SJ, Jessen WJ, Mehta T, Hardiman A, Sites E, Kaiser S, Jegga AG, Li H, Upadhyaya M, Giovannini M, Muir D, Wallace MR, Lopez E, Serra E,

Nielsen GP, Lazaro C, Stemmer-Rachamimov A, Page G, Aronow BJ, Ratner $\mathrm{N}$ : Integrative genomic analyses of neurofibromatosis tumours identify SOX9 as a biomarker and survival gene. EMBO Mol Med 2009, 1:236-248.

19. Ottini L, Esposito DL, Richetta A, Carlesimo M, Palmirotta R, Verí MC, Battista P, Frati L, Caramia FG, Calvieri S, Cama A, Mariani-Costantini R: Alterations of microsatellites in neurofibromas of von Recklinghausen's disease. Cancer Res 1995, 55:5677-5680.

20. Scott RH, Mansour S, Pritchard-Jones K, Kumar D, MacSweeney F, Rahman N: Medulloblastoma, acute myelocytic leukemia and colonic carcinomas in a child with biallelic MSH6 mutations. Nat Clin Pract Oncol 2007, 4:130-134.

21. Bandipalliam P: Syndrome of early onset colon cancers, hematologic malignancies \& features of neurofibromatosis in HNPCC families with homozygous mismatch repair gene mutations. Fam Cancer 2005, 4:323-333.

22. Lubinsky MS: Non-random associations and vascular fields in neurofibromatosis 1: a pathogenetic hypothesis. Am J Med Genet A 2006, 140:2080-2084

23. Wistuba II, Tomlinson GE, Behrens C, Virmani A, Geradts J, Blum JL, Minna JD, Gazdar AF: Two identical triplet sisters carrying a germline BRCA1 gene mutation acquire very similar breast cancer somatic mutations at multiple other sites throughout the genome. Genes Chromosomes Cancer 2000, 28:359-369.

24. Delgado L, Fernández G, González A, Bressac-de Paillerets B, Gualco G Bombled J, Cataldi S, Sabini G, Roca R, Musé IM: Hereditary breast cancer associated with a germline BRCA2 mutation in identical female twins with similar disease expression. Cancer Genet Cytogenet 2002, 133:24-28.

\section{Pre-publication history}

The pre-publication history for this paper can be accessed here: http://www.biomedcentral.com/1471-2407/10/407/prepub

doi:10.1186/1471-2407-10-407

Cite this article as: Melean et al: Monozygotic twins with

Neurofibromatosis type 1, concordant phenotype and synchronous development of MPNST and metastasis. BMC Cancer 2010 10:407.

\section{Submit your next manuscript to BioMed Central and take full advantage of:}

- Convenient online submission

- Thorough peer review

- No space constraints or color figure charges

- Immediate publication on acceptance

- Inclusion in PubMed, CAS, Scopus and Google Scholar

- Research which is freely available for redistribution 